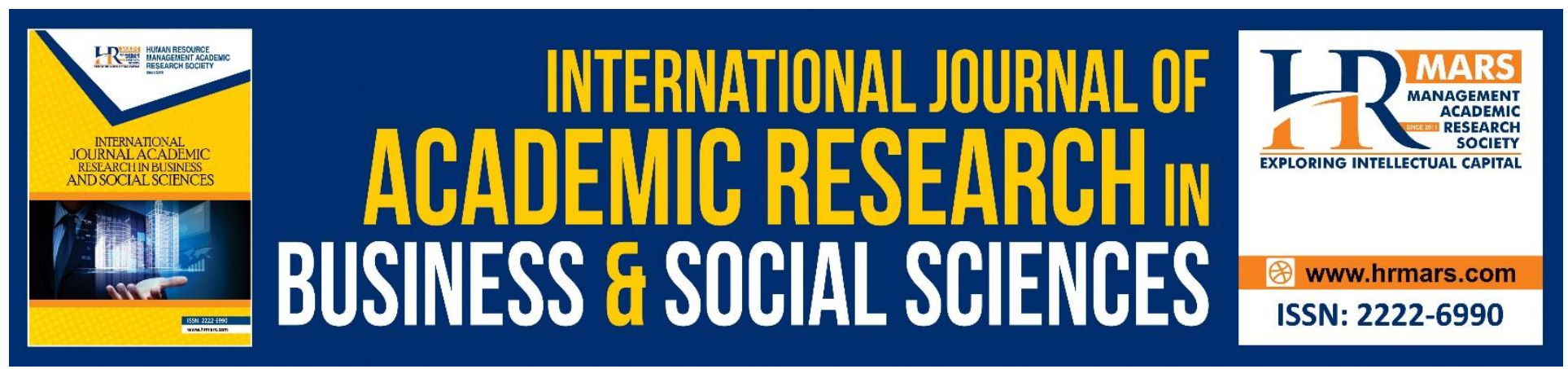

\title{
Guided Cooperative Flipped Classroom Approach in Learning Molecular Orbital Theory
}

Sharipah Ruzaina Syed Aris, Muhamad Furkan Mat Salleh, and Mohamad Hisyam Ismail

To Link this Article: http://dx.doi.org/10.6007/IJARBSS/v10-i14/7689 DOI:10.6007/IJARBSS/v10-i14/7689

Received: 23 April 2020, Revised: 20 May 2020, Accepted: 01 June 2020

Published Online: 04 July 2020

In-Text Citation: (Aris et al., 2020)

To Cite this Article: Aris, S. R. S., Salleh, M. F. M., \& Ismail, M. H. (2020). Guided Cooperative Flipped Classroom Approach in Learning Molecular Orbital Theory. International Journal of Academic Research in Business and Social Sciences, 10(14), 200-212.

Copyright: (c) 2020 The Author(s)

Published by Human Resource Management Academic Research Society (www.hrmars.com)

This article is published under the Creative Commons Attribution (CC BY 4.0) license. Anyone may reproduce, distribute, translate and create derivative works of this article (for both commercial and non-commercial purposes), subject to full attribution to the original publication and authors. The full terms of this license may be seen at: http://creativecommons.org/licences/by/4.0/legalcode

Special Issue: WSTI2018 - Issues and Trends on Education, Science and Technology, 2020, Pg. 200 - 212 http://hrmars.com/index.php/pages/detail/IJARBSS JOURNAL HOMEPAGE

Full Terms \& Conditions of access and use can be found at http://hrmars.com/index.php/pages/detail/publication-ethics 


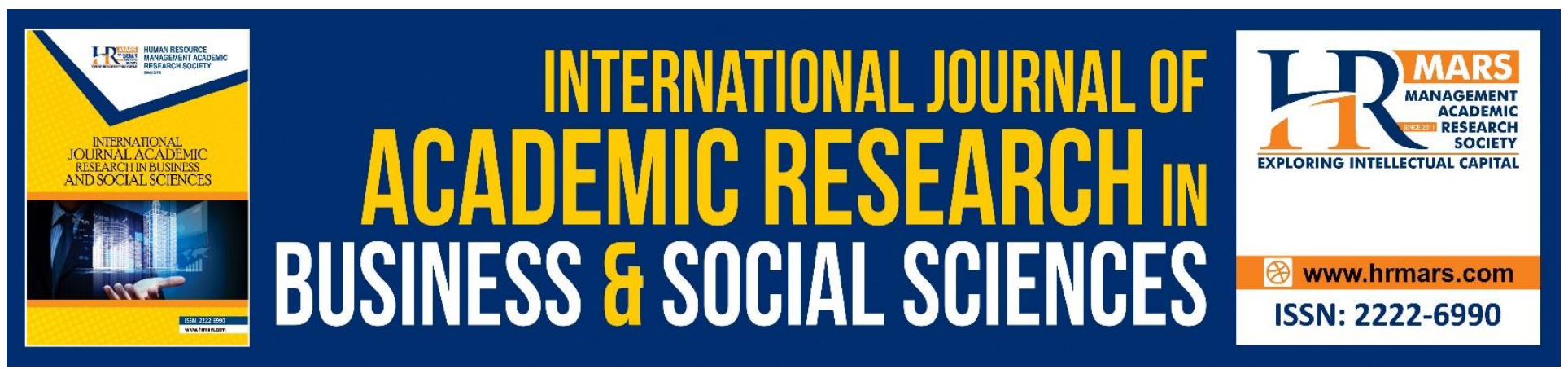

\title{
Guided Cooperative Flipped Classroom Approach in Learning Molecular Orbital Theory
}

\author{
Sharipah Ruzaina Syed Aris, Muhamad Furkan Mat Salleh, \\ and Mohamad Hisyam Ismail \\ Science Education Department, Faculty of Education, Universiti Teknologi MARA, Cawangan \\ Selangor, Kampus Puncak Alam, 42300 Bandar Puncak Alam, Selangor
}

\begin{abstract}
The purpose of the study is to investigate whether innovative approach called Guided Cooperative Flipped Classroom can be accepted by students during the learning of Molecular Orbital. Molecular Orbital theory is one of the topics teach in Inorganic Chemistry. This course is enrolled by pre-service science teacher major or minor in chemistry. Although Flipped Classroom has been widely accepted, this is the first time the approach experienced by the students. Unlike other courses, students always have a negative perception toward chemistry course, for example chemistry subject is difficult to understand and is not easy to pass. Case study approach was adopted to discover students' acceptance on the approach through survey and informal interview. The study was carried out with four guided learning steps: Intentional Content Approach, Higher Order Thinking Activities, Sharing and Feed-Forward Feedback Session and Reflection Session. In general, majority of the students perceived positive direction towards the approach and belief that the approach support and engage them in learning inorganic chemistry much better compare to traditional way of learning. Some of the students feel that, this is the first time that they learn chemistry meaningfully. It can be concluded that the Guided Cooperative Flipped Classroom is acceptable as an alternative approach in understanding Molecular Orbital Theory.
\end{abstract}

Keywords: Guided Cooperative Flipped Classroom, Molecular Orbital Theory, Action Research, Higher Order Thinking Activities.

\section{Introduction}

Many students are having difficulty in understanding Chemistry subject which resulted in poor performance (Abeysekera \& Dawson, 2015). They also perceived that chemistry as one of the difficult subjects. In general, there are four factors that contribute to learning difficulties perceived by educators, which are learning environment, nature of the course, student and academic staff (Awidiya \& Paynterb, 2019). Educators belief that, chemistry should be taught in varieties of delivery mode and engage students with more activities. Table 1.0 below summarize among the reason why chemistry remark as difficult subject (Awidiya \& Paynterb, 2019; Bishop \& Verleger, 2013; Cardellini, 2012; Cha \& Kim, 2013; Cormier \& Voirsard, 2018). 
INTERNATIONAL JOURNAL OF ACADEMIC RESEARCH IN BUSINESS AND SOCIAL SCIENCES

Vol. 10, No. 14, Special Issue: WSTI2018 - Issues and Trends on Education, Science and Technology, 2020, E-ISSN: 2222-6990 @ 2020 HRMARS

Table 1.0: Summary of Factors Contribute to Difficulty in Chemistry

\begin{tabular}{|c|c|c|c|}
\hline $\begin{array}{c}\text { Learning } \\
\text { environment }\end{array}$ & Educators & Students & Content-Laden \\
\hline $\begin{array}{l}\text { - Teacher centered } \\
\text { - Lack of teaching } \\
\text { aids } \\
\text { - Lack of } \\
\text { continuous } \\
\text { assessment }\end{array}$ & $\begin{array}{l}\text { - Passive, No } \\
\text { activity } \\
\text { - } \quad \text { No interaction } \\
\text { with real life } \\
\text { - Lack of teaching } \\
\text { strategy }\end{array}$ & $\begin{array}{l}\text { - Lack of } \\
\text { motivation and } \\
\text { interest } \\
\text { - Difficulty in } \\
\text { understanding } \\
\text { chemistry } \\
\text { language } \\
\text { - Limited } \\
\text { preparation }\end{array}$ & $\begin{array}{l}\text { Microscopic, } \\
\text { macroscopic and } \\
\text { symbolic } \\
\text { presentation }\end{array}$ \\
\hline
\end{tabular}

Few studies addressed the importance and difficulty in learning inorganic chemistry particularly Molecular Orbital Theory (MOT). This study will look into how alternative teaching can help students in their MOT learning. In order to understand better MOT, students need to master models of atomic structure, effective core charge and quantum mechanics (Fautcha, 2017; Foldnes, 2016). Chemical bonding theory is also extensive part in chemistry that students need to have as their prior knowledge before they can pursue to explain advance chemical phenomena.

As been highlighted, the way chemistry been taught is important in chemistry learning. In addressing new millennia, teacher-centered approach is no longer acceptable. Active learning pedagogy which allow student centric approach and peer interaction known to improve students learning outcome (Salleh et al., 2014). Several alternative approaches in teaching and learning chemistry have been crafted by passionate researchers and educators such as Problem Based Learning (Johnson, 2013; Lin et al., 2016). Inquiry Based Learning and Cooperative/ Collaborative Learning (Munir et al., 2018; Poe, 2015). Study shown that cooperative learning is the most preferred approach in chemistry class especially in promoting conceptual change (Rahhoua et al., 2015).

Flipped classroom is an example of blended learning approach that is currently being considerable in education arena. The term flipping classroom reverse form traditional way of teaching. In this situation, students learn on their own outside classroom through digital media and discuss with peers and educators during classroom with more engaging activities to achieve the lesson outcomes. In other words, reinforcement of subject matter is made in the classroom, while lecturing takes place outside the classroom. A group of researchers defined flipped classroom "as an educational technique that consists of two parts: interactive group learning activities inside the classroom, and direct computer-based individual instruction outside the classroom" (Rodriguez, 2015). Meanwhile, another group of researchers define more precisely the flipped classroom as: a "set of pedagogical approaches that (1) move most information-transmission teaching out of class; (2) use class time for learning activities that are active and social and (3) require students to complete pre-and/or post-class activities to fully benefit from in-class work" (p. 3) (Bishop \& Verleger, 2013).

According to Schell \& Mazur (2015), there are three big ideas about flipped classroom. Firstly, prior knowledge is important to scaffold deep learning, secondly, students learn best when they are engaged which create opportunity for social interaction and experiential learning. The third big idea is flipped enable a sustained learning path where learning is extended outside classroom (Smith, 2013). Studies on flipped classroom in chemistry subject is not as extensive as other area. However, 
several findings reported on the positive effect of flipped classroom in the learning of chemistry. Flipped classroom resulted improvement in students' understanding in organic chemistry and upgrading their ability in problem solving (Cha \& Kim, 2013; Supasorn et al., 2014; Tsaparlis \& Sevian, 2013; Warfa, 2015). Students also perceived positive impression towards flipped classroom because more time were spent for explanation, interaction with peers and practice in class. It is also reported that flipped classroom helped to develop thinking and problem solving skills, critical analysis skills and improved communication and teamwork skills. In addition, it helps students to be more selfdiscipline and responsible in their own learning.

This study intended to obtain students acceptance on Flipped Classroom as an alternative teaching approach in learning Molecular Orbital Theory which is called Guided Cooperative Flipped Classroom. The reason why researcher introduced GCFC approach is to find different way in teaching especially in dealing with new millennia that have totally different characteristic. As an educator, traits of this young generation such as they love their gadget very much, love to interact with their peers, and flexibility should be counted when crafting teaching delivery.

The main concept of Flipped Classroom is to spend more time in doing higher order thinking activities in the classroom such as answering questions, peer interaction, and small group discussion. Meanwhile, lower order activity like understanding and comprehending knowledge happen outside the classroom which so called Non-Face-to-Face activity.

\section{Guided Cooperative Flipped Classroom Approach (GCFC)}

There are four sessions in the GCFC approach; Intentional Content Approach, Higher Order Thinking Activities, Sharing and Feed-forward Feedback Session and Reflection Session. Diagram 2.0 describe the GCFC approach.

The word "guided" because students still need a teacher to guide them especially when they need further explanation and when the students are holding misconception. 


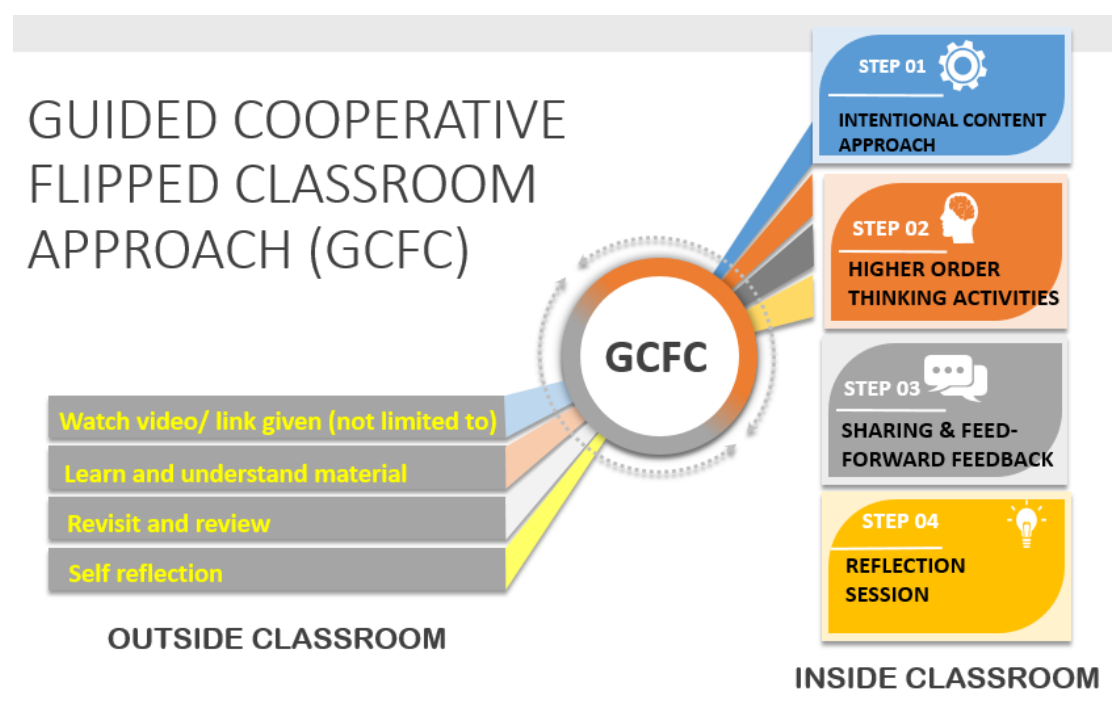

\section{Diagram 2.0 GCFC Approach}

\section{Outside Classroom}

The lecturer uploaded material in university Learning Management System platform, called iLearn Portal (Diagram 2.1). Materials uploaded are in the form of power point presentation, exercise sheet, and notes that have been prepared by a team of lecturer who teach Inorganic Chemistry subject. On top of that appropriate video also link and share in the iLearn. Video/Youtube link are mostly from Khan Academy, Socratica, ChemisNate, and Ben's Chem Videos. These video were choosing because of the clear and easy explanation.
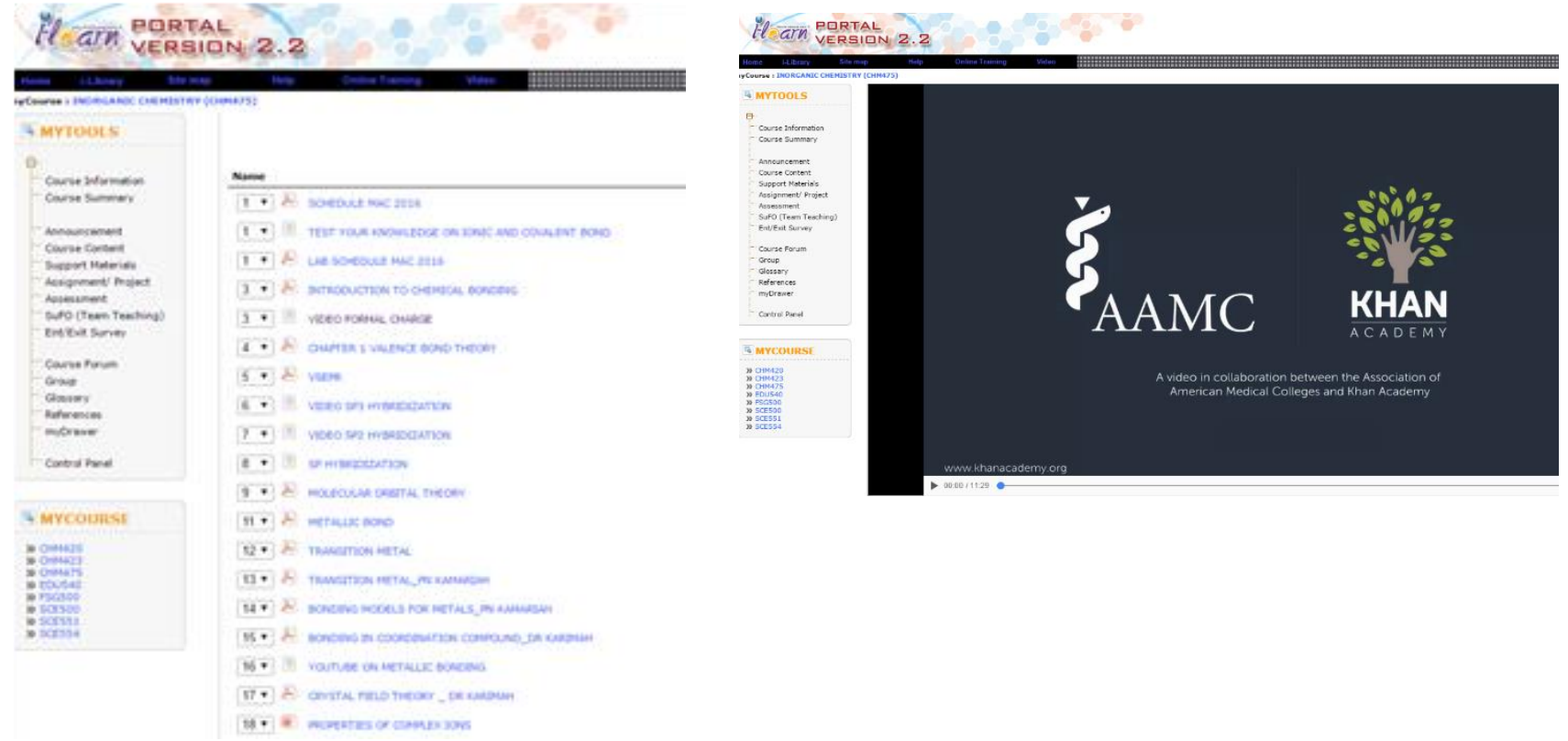

\section{Diagram 2.1: iLearn Portal (University LMS) \& Khan Academy Video link to iLearn Portal}

\section{Session 1: Intentional Content}

Intentional Content Approach is a two-way interaction among peers and lecturer. The session took around 15 to 30 minutes. This session allows students to gain deep understanding on the gist of the concept in Molecular Orbital in a small group. The small group is formed based on a combination 
among weak, average and good students. This was identified through their previous test result. Mini lecture between 15-20 minutes is allocated to explain further on a certain concept if required by students. Students were also encouraged to use their smart phone to look for uncertain terminology, definition or when quick clarification is needed along the way.

\section{Session 2: Higher Order Thinking Activities}

Students have to work out on the exercise/questions assigned to them. They need to solve the problems independently before discuss with the rest of other members in the group. In the next30-45 minutes, they have to share their answer/ solution to the rest of other members in the group. Most of the questions given to the students were taken from past years examination and questions from suggested main text book. Diagram 2.2 is examples of questions given to students for them to work on individually before discuss with their friends.

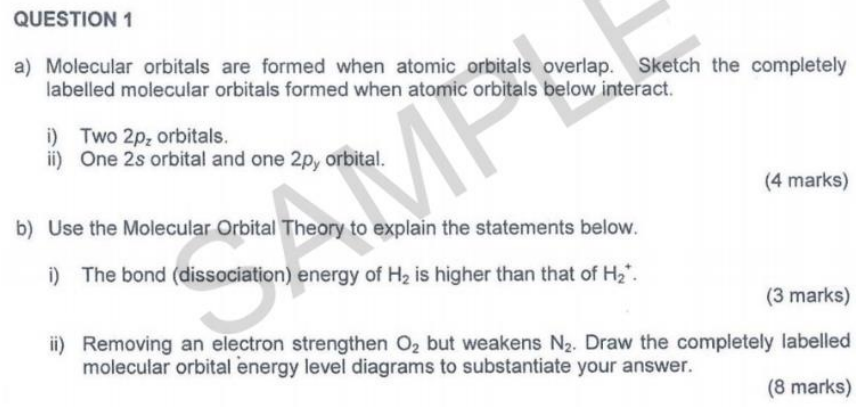

\section{Diagram 2.2 Example of Exercise given to students}

\section{Session 3: Sharing and Feedforward Feedback Session}

During this session, students voluntarily write down the solution on the white board, while the other students were listening and checking their own answer at the same time. This session took about 30-40 minutes. Students who failed to obtain the correct answer will discuss with either their peers or with lecturer. Below is the example of solution discussed by the students among their peers.
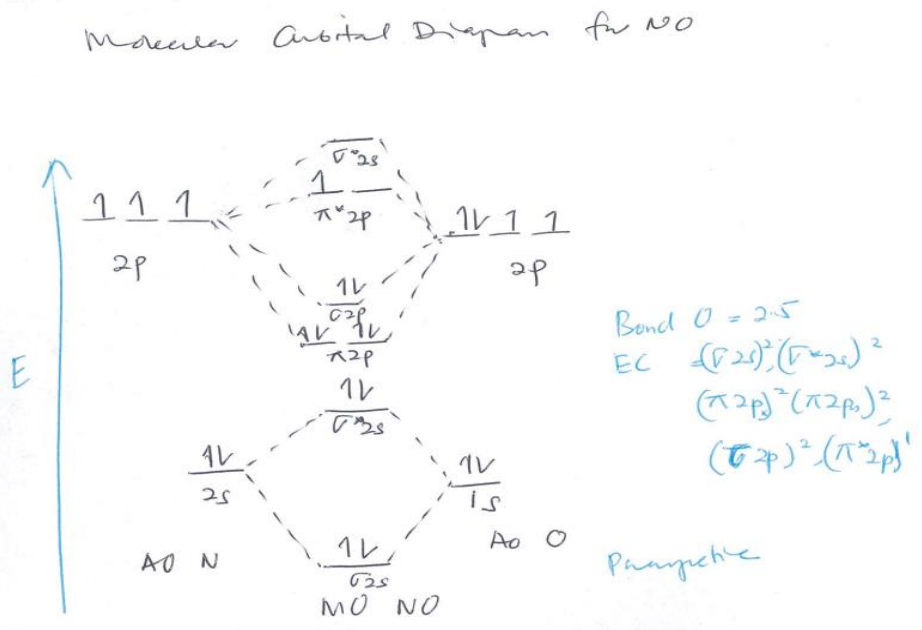

Session 4: Reflection Session 
This session took about 10-15 minutes to wrap up what have been covered for the day. During this session, students were asked to identify their weakness. They were encouraged to go back and revisit video or power point presentation uploaded in the iLearn portal. The four guided learning steps are repeated for each two-hour learning session.

\section{Research Questions}

The research questions of the study are:

1. What are students' feedbacks on the GCFC model used during the learning of Molecular Orbital Theory?

2. Do students perceive that the GCFC model help students to support their learning in Molecular Orbital Theory?

\section{Methodology}

Design

The study used intrinsic case study as the research approach in investigating the acceptance of Guided Cooperative Flipped Classroom in the learning of Molecular Orbital Theory. This approach is used due to researchers' interest in applying various teaching and learning strategy to help students understand chemistry in a better way.

\section{Sample}

A group of 24 students from Science Education program (pre-service science teacher program) participated in the study. The students enrolled in Inorganic Chemistry class as their minor subject.

\section{GCFC Implementation}

The students were exposed to Guided Cooperative Flipped Classroom during the learning of Molecular Orbital Theory, Isomerism and Bonding Theory. However, for the purpose of this paper, the discussion will focus on students' involvement and their feedback toward learning Molecular Orbital Theory (MO). The study took place in the fourth and fifth week of second semester 2017. Two class sessions for two hours each needed to cover MO Theory. During the 6 hours study duration, students were exposed to GCFC approach (Refer Section 2.0 in this paper).

\section{Survey Questionnaire}

A questionnaire was developed through modification from several studies [21] [22]. The questionnaire consisted of 10 items on students' perception of GCFC model and whether the model can help them during the learning of MO theory. Five point Likert scale questionnaire was administered to students through google form with " 1 " being strongly disagree and " 5 " being strongly agree. Five questions address Research Question 1 and the next five questions addressed Research Question 2. The questions were randomly place in the form. Below are the examples of questions ask to the students:

1. The GCFC is more engaging than traditional classroom instruction

2. GCFC help me to increase my understanding in learning inorganic chemistry

3. Feedback from friends during the GCFC help improving my understanding in the topic 


\section{Interview}

Interview was conducted to gain in depth experience of students during the exposure of GCFC. Nine students were selected for the interview session with a combination of three low achievers, three medium achiever and three higher achiever students. The students were asked on their experienced, the advantage and disadvantages of the GCFC approach.

\section{Results and Discussion Quantitative Result}

In general, majority of the students have positive perception towards the GCFC experience and data shows to the end of the agree spectrum. The two figure below (Figure 4.1 and Figure 4.2) illustrated percentage of students perception on GCFC.

\section{Figure 4.1 Students Feedback on GCFC (\%)}

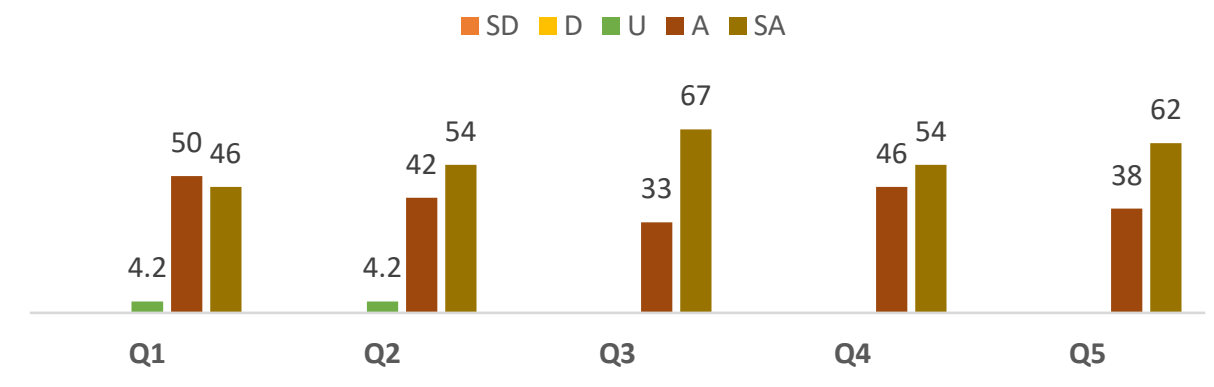

Note: $\mathrm{SD}=$ Strongly disagree; $\mathrm{D}=$ Disagree; $\mathrm{U}=$ unsure; $\mathrm{A}=$ Agree; $\mathrm{SA}=$ Strongly Agree

Based on Figure 4.1, shows students responses data on their feedback on GCFC approach. It shows that $46 \%$ strongly agree and $50 \%$ agree that GCFC approach more engaging than traditional classroom instruction. This result come to an agreement with Smith (2013) who conducted research to determine students' attitude toward flipped classroom. Meanwhile, the result shows that 54\% strongly agree and $42 \%$ agree that GCFC approach provide better experience in learning MO theory. All of the students strongly agree and agree that GCFC approach allow them greater opportunity to communicate with other students in the classroom. They also perceived that they are all motivated and enjoy participating in GCFC classroom. The finding of this research is coincide with study done by other researchers (Cardellini, 2012; Cha \& Kim, 2013; Supasorn et al., 2014; Tsaparlis \& Sevian, 2013; Warfa, 2015; Woldeamanuel et al., 2014; Yestrebskya, 2015) where the feedback is positive toward the flipped classroom approach which eventually improve students' attitude and increase their confident in learning chemistry (Cardellini, 2012). 


\section{Figure 4.2 GCFC Support Students Learning (\%)}

$$
\square \mathrm{SD} \square \mathrm{D} \square \mathrm{U} \square \mathrm{A} \square \mathrm{SA}
$$

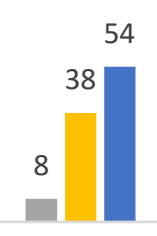

Q1

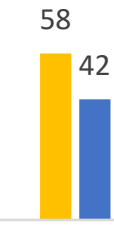

Q2

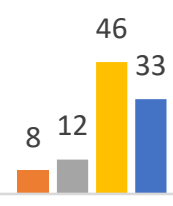

Q3

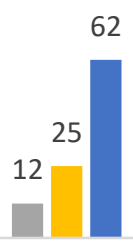

Q4

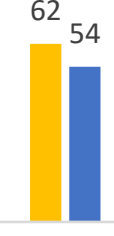

Q5

Note: $S D=$ Strongly disagree; $D=D i s a g r e e ; U=$ unsure; $A=A g r e e ; S A=$ Strongly Agree

Figure 4.2 represents students' perception whether GCFC support their learning in chemistry MO theory. In general, majority students' belief that the approach supports their learning in MO theory which is similar to a finding by another group of researcher (Woldeamanuel et al., 2014). In response to Q1, the data indicates $92 \%$ skewed to right band, where students agreed that the approach prepared them well before coming to the class. Meanwhile, $8 \%$ were unsure whether GCFC help prepare them for the next class. Majority of them also agreed that the approach help them understand the subject better (Q4). All students agree that the approach help them learn best with their peers (Q2) and feedback given during the group session helps them improved their understanding in the subject (Q5). The result echo with other previous findings (Cardellini, 2012; Yusuf, 2013). Despite of higher proportion agreed (79\%), 8\% students disagree that material uploaded in the university LMS portal provide necessary information for them to be successful in the course (Q3). Table 4.1 and 4.2 tabulated mean score of each item in the questionnaire. The data indicated that Q3, (Table 4.1) "The GCFC gives me greater opportunity to communicate with other students" receives the highest mean score followed by Q5 (Table 4.1) "I enjoy participating in GCFC class" compared to the rest of other questions. Meanwhile, "Material uploaded in the ILearn portal provide necessary information to successful in the course" Q3 (Table 4.2) received the lowers mean score compare to the rest of other questions.

Table 4.1 Mean Score of Students Feedback on GCFC

\begin{tabular}{llc}
\hline \multicolumn{2}{l}{ Items on Students Feedback on GCFC } & Mean \\
\hline Q1 & The GCFC is more engaging than traditional classroom instruction. & Score \\
Q2 & The GCFC provide better learning experience & 4.42 \\
Q3 & $\begin{array}{l}\text { The GCFC gives me greater opportunity to communicate with other } \\
\text { students }\end{array}$ & 4.50 \\
Q4 I am more motivated in learning inorganic chemistry through GCFC & 4.67 \\
Q5 $\quad$\begin{tabular}{l} 
I enjoy participating in GCFC class \\
\hline
\end{tabular}
\end{tabular}


Table 4.2 Mean Score of Students Feedback on GCFC

\begin{tabular}{lll}
\hline Items on GCFC support students learning & Mean Score \\
\hline Q1 & GCFC prepared me well before coming to the class & 4.42 \\
Q2 & $\begin{array}{l}\text { I learn best during group discussion } \\
\text { Q3 }\end{array} \quad \begin{array}{l}\text { Material uploaded in the ILearn portal provide necessary information to } \\
\text { successful in the course }\end{array}$ & 4.42 \\
Q4 & $\begin{array}{l}\text { GCFC help me to increase my understanding in learning inorganic chemistry } \\
\text { Q5 } \quad \begin{array}{l}\text { Feedback from friends during the GCFC help improving my understanding in } \\
\text { the topic }\end{array}\end{array}$ & 4.04 \\
\hline
\end{tabular}

\section{Qualitative Result}

Nine students were interviewed with a mix composition of low achiever, medium achiever and high achiever. One of the students who disagree on material uploaded also being called for interview to gain deeper insight on his experienced. Semi structured questions were asked during the interview. Example of the questions asked are listed below:

1. What is your experienced during the GCFC approach?

2. Among the four sessions which session do you like most? And can help you in your learning?

3. What about the materials uploaded in the iLearn portal? Does it help you a lot?

4. Should the GCFC being continued?

\section{Question "What is your experienced during the GCFC approach"}

Students response of the above question:

All the students said that this is their first time experience such approach especially in learning chemistry. The answer trend of students is almost the same.

Student 1b (High Achiever):

"In my opinion, I like the approach. I have not experienced such approach. But I have attended Blended Learning class ...but the approach in our class is different...I think it is very meaningful"

Student 2a (Medium Achiever)

"I think I enjoy the class, especially when working with group member... I can compare my answer with my friends and learn a lot from them... thank you Dr for giving me opportunity to gain this experience"

\section{Student 3a (Low Achiever)}

"This is something new to me... all this while I am not sure how to study chemistry... learn a lot from this approach...I like the approach..it seems like first time I learning chemistry with fully engagement.." 


\section{Question "Among the four sessions which session do you like most? And can help you in your} learning"

Students respond to the above question:

Majority of the students said that the session they like most is during peer interaction session. They also like when they can easily watch video anytime anywhere they like and the watch-pause-rewindwatch concept.

Student 1c (High Achiever)

"I like all the sessions... particularly during group session...I like to help my friends in my group... we getting much closer and actually learn from each other.."

Student 2b (Medium Achiever)

"I think it is a good combination...each session is meaningful to me.. very structured kind of learning... and I think I learn better and I can see that my test result increase...think I like most is when we go to in front of the class ..share our answers on the board and we learn from each other... comparing answer...you assist us especially a student like me ..i am not good especially in chemistry"

Student 3c (Low Achiever)

"At first I am kind of shock... especially when I have to prepare in advance... I am quite of struggling learning alone...I need more guidance... but in class session is where I learn a lot...I learn a lot with my friends especially good ones...l know that my result is improving a bit...l still need to learn a lot"

\section{Question: What about the materials uploaded in the iLearn portal? Does it help you a lot?}

Students respond:

In general, all students agree with the material uploaded and perceived that the materials uploaded like video, power point presentation, warm-up quiz/test help them during their learning process. Especially when they can learn anytime anywhere, play-pause-play concept. However, one of the students interviewed respond contrasted from others.

\section{Student 3b (Low Achiever)}

I think in general..material uploaded help ..but understanding the material and video is challenging to me because the language is not easy to understand...I have to re watch over and over again.. and it takes a lot of my time... and sometimes...internet connection is very poor

The above perception echo with other students from other study who said that they must prepare a lot before coming to the class (Cha \& Kim, 2013). However, students from different study perceived in a different way where they felt that the approach is giving them less homework compared to traditional class (Woldeamanuel et al., 2014).

\section{Question: Should the GCFC being continued?}

Students respond:

All the students interviewed consistent with their respond that GCFC should be continued especially to other subjects. The students also suggested that the internet connectivity should be improved in other to make the approach more efficient. One of the medium achiever students reacted that the 
approach might not be suitable to all subjects especially difficult subject such as that actually need more guidance.

Student 2c (Medium achiever)

I am not quite sure...but I think we can continue with the approach in our class...but might not suit for all subject especially difficult subject or topic...like physical chemistry.

\section{Conclusion}

Guided Cooperative Flipped Classroom which was first introduced during the learning of chemistry is being acceptable by the students. In general, they are positive with the approach. The students persistent with their answer because they can see that the approach benefited them in the learning. They enjoy and being motivated with the new dimension of learning, because the approach addressed their young generation traits that allow them to be more centric, engage interactively in their own manner and learning along with peers. The finding of the current study, supported statement by Mazur in early 1990s that peer instruction and feedback as the key component in flipped classroom. He also believed that this approach will eventually disrupt obsolete conventional instruction. The study also supported theories of Piaget 1967 and Vygotsky 1978 on students centered and peer-assisted learning. Students also perceived that structured GCFC approach support them in learning chemistry in term of make them to be prepared before coming to the class, supporting material and generous friends, a series of formative assessment and reflection session help to improve their performance in learning chemistry which has been perceived as difficult by majority of students around the world. However, there are still room for improvement that need to be considered for more efficient and smooth learning process. There are, material uploaded should be thoroughly suggested in order to suit different ability of students, improve campus infrastructure particularly the internet connection.

\section{References}

Abeysekera, L., \& Dawson, P. (2015). Motivation and cognitive load in the flipped classroom: definition, rationale, and a call for research. Higher Educ. Res. Dev. 34, 1-14. doi:10.1080/07294360.2014.934336.

Awidia, I. T., \& Paynterb, M. (2019). The impact of a flipped classroom approach on student learning experience. Computers \& Education, 128, 269-283.

Bishop, J. L., \& Verleger, M. A. (2013). The Flipped Classroom: A Survey of the Research. Unpublished manuscript, American Society for Engineering Education, $12^{\text {th }}$ ASEE Annual Conference and Exposition.

Cardellini, L. (2012). Chemistry: Why the Subject is Difficult? Educación Química, 23, 305-310. 10.1016/S0187-893X(17)30158-1

Cha, J., \& Kim, H. B. (2013). Flipping organic chemistry course: Possibilities and challenges. International Conference on Chemical Engineering and Bioprocess Engineering. Institute of Physics (2016). IOP Conference Series. Earth and Environmental Science 36, 012013. doi:10.1088/1755-1315/36/1/012013.

Cormier, C., \& Voisard, B. (2018). Flipped Classroom in Organic Chemistry Has Significant Effect on Students' Grades. Front. ICT 4:30. doi: 10.3389/fict.2017.00030. 
Fautcha, J. M. (2015). The flipped classroom for teaching organic chemistry in small classes: is it effective? Chemistry Education Research and Practice 16(1), 179-186.

Foldnes, N. (2016). The flipped classroom and cooperative learning: evidence from a randomized experiment. Active Learning in Higher Education, 17,39-49.

Gurses, A., Dogar, C., \& Geyik E. (2015). Teaching of the Concept of Enthalpy Using Problem Based Learning Approach. Procedia - Social and Behavioral Sciences 197, 2390-2394.

Johnson, G. B. (2013). Student Perceptions of The Flipped Classroom. Unpublished Master's thesis, The University of British Columbia.

Lin, J. W., Yen, M. H., Liang, J. C., Chiu, M. H., \& Guo, C. J. (2016). Examining the Factors That Influence Students' Science Learning Processes and Their Learning Outcomes: 30 Years of Conceptual Change Research. Eurasia Journal of Mathematics, Science \& Technology Education, 12(9), 2617-2646.

Munir, M. T., Baroutian, S., Young, B. R., \& Carter, S. (2018). Flipped classroom with cooperative learning as a cornerstone. Education for Chemical Engineers, 23, 25-33.

Poë, J. C. (2015). Active Learning Pedagogies for the Future of Global Chemistry Education. In J. G. Mart'inez \& E. S. Torregrosa, Chemistry Education: Best Practices, Opportunities and Trends (pp. 279-299). Germany: Wiley-VCH Verlag GmbH \& Co.

Rahhoua, A., Kaddaria, F., Elachqara, A., \& Oudrhiria, M. (2015). Infinity Small Concepts in The Learning of Chemistry. Procedia - Social and Behavioral Sciences 191, 1337 - 1343.

Rodríguez, C. M., Corona, L. B., \& Ibáñez, M. V. (2015). Cooperative Learning in the Implementation of Teaching Chemistry (Didactic Instrumentation) in Engineering in México. Procedia - Social and Behavioral Sciences, 174, 2920-2925.

Salleh, M. F. M., Abdullah, N., Alias, N. A., \& Ismail, M. H. (2014). Malaysian and Steiner Waldorf Science Curricular Practices: A Comparative Study and Implications for The Design of Science Teacher Education. STEM Planet Journal 1, 1-12.

Schell, J., \& Mazur, E. (2015). Flipping the Chemistry Classroom with Peer Instruction. In J. G. Mart'ınez \& E. S. Torregrosa, Chemistry Education: Best Practices, Opportunities and Trends (pp. 319-329). Germany: Wiley-VCH Verlag GmbH \& Co.

Smith, J. D. (2013). Student attitudes toward flipping the general chemistry classroom. Chemistry Education Research and Practice, 14, 607-614.

Supasorn, S., Kamsai, L., \& Promarak, V. (2014). Enhancement of learning achievement of organic chemistry using inquiry-based semi-small-scale experiments (SSSEs). Procedia - Social and Behavioral Sciences 116, 769-774.

Tsaparlis, G., \& Sevian, H. (2013). Concept of Matter in Science Education. Innovation in Science Education Technology 19. Springer.

Warfa, A. R. M. (2015). Using Cooperative Learning to Teach Chemistry: A Meta-analytic Review. Journal of Chemical Education, 93(2), 248-255. doi: 10.1021/acs.jchemed.5b00608.

Woldeamanuel, M. M., Atagana, H., \& Engida, T. (2014). What Makes Chemistry Difficult? AJCE 4(2), Special Issue, ISSN 2227-5835.

Yestrebskya, C. L. (2015). Flipping the Classroom in a Large Chemistry Class-Research University Environment. Procedia - Social and Behavioral Sciences, 191, 1113-1118.

Yusuf, S. D. (2013). Effects of Using Gagne's Learning Hierarchy on Chemistry Students' Academic Achievement and Anxiety Level in Balancing Chemical Equations In Secondary Schools In Katsina Metropolis, Nigeria. IOSR Journal of Applied Chemistry, 5(4), 10-15. 